\title{
AULA-COMO-ARTE EM ALIANÇA TÁTICA COM A URGÊNCIA DE UMA PESQUISADORA-DOCENTE- CRIADORA
}

\section{CLASS-AS-ART IN A TACTICAL ALLIANCE WITH THE URGENCY OF A RESEARCHER-TEACHER- CREATOR}

\author{
Thaise Luciane Nardim \\ thaise@uft.edu.br \\ Universidade Federal do Tocantins - UFT, Câmpus de Palmas
}

\section{Resumo:}

O texto introduz as noções de pesquisa pós-qualitativa e pesquisa-docência-criação, propondo o pensamento acerca das possibilidades de relação entre a aula-como-arte em suas qualidades de difícil quantificação e as urgências e imediatitudes da vida-mesma, a partir do contexto de aulas ministradas num curso de Licenciatura em Teatro. Após apresentar elementos componentes de uma aula-como-arte, expõe a experiência, realizada pela autora, de composição de objetivos de aprendizagem e critérios de avaliação consonantes à proposta de uma aula-de-teatro-como-arte, orientando-se à reflexão sobre modos pelos quais a arte pode infiltrar-se-em e hackear-as instituições de ensino.

Palavras-chave: aliança tática, pedagogia do teatro, pesquisa-docência-criação, pesquisa pósqualitativa.

\section{Abstract:}

The paper introduces the notions of post-qualitative research and research-teaching-creation, leading to reflections on the relationships between the class-as-art, in its qualities of difficult quantification, and the immediate urgencies of life, in the context of classes given in a Theater Degree course. After presenting component elements of a class-as-art, the text exposes the experience, carried out by the author, of composing learning objectives and assessment criteria in line with the proposal for a theater-as-art-class, guiding reflections on the ways in which art can infiltrate and hack educational institutions.

Keywords: drama teaching, post-qualitative research, research-teaching-creation, tactical alliance.

\section{Introdução}

O texto que ora escrevo - ou ainda, o texto que você, pessoa leitora, ora encontra ou confronta - é, sim, um texto acadêmico. Está sendo (ou foi) escrito por uma professora universitária; resulta de uma pesquisa realizada em contexto universitário e fundada em métodos; contudo, não recorre à linguagem e à forma tradicionalmente consagradas do fazer-texto universitário. Isso porque as relações que ele e eu, texto e autora, estabelecemos com a pesquisa universitária são balizados por um conjunto de pensamentos e modos de entender tanto a pesquisa, quanto a 
docência e a criação, que diferem muito daqueles pensamentos e modos de entendimento que forjaram a produção acadêmica tradicional e consagrada.

A metodologia à qual nos subscrevemos vem sendo chamada, por autoras com quem nos identificamos (o texto e eu) e com as quais buscamos dialogar, de pós-qualitativa (ST. PIERRE, 2017). Nas habituais aulas de metodologia científica dos cursos de graduações brasileiros, assim como nos livros-texto que a elas dão sustentação, em geral nós, professores, apresentamos a díade "quantitativa - qualitativa" para caracterizar naturezas de metodologias prevalecente. $\mathrm{O}$ discurso praticado informa que a primeira seria orientada a análises numéricas, de quantidades, proporções, estatísticas, frequências; e a segunda, a qualidades, isto é, às características menos exatas e mais humanas das coisas do mundo, permitindo aproximações subjetivas e métodos e técnicas um pouco menos laboratoriais.

Dado que o objetivo deste texto não repousa no tema mesmo das metodologias, quero que esteja evidente que as descrições que acima utilizei são extremamente insuficientes; são ligeiras, superficiais e quase irresponsáveis. São, de fato, o senso comum sobre essas metodologias. Contudo, para que você, pessoa leitora, possa seguir em boa experiência com o que proponho, considero que preciso cometer essa grosseria para, enfim, introduzi-la à metodologia de pesquisa pós-qualitativa e, então, liberá-la para a apreciação das ideias que seguem.

Destaco como principal característica da pesquisa pós-qualitativa a recusa de um método pré-existente. Aquilo que será feito no processo de pesquisa não deve copiar procedimentos realizados anteriormente por outros pesquisadores, ainda que em campo próximo, e ainda que bem sucedidos (ST. PIERRE, 2017). Isso porque parte-se da noção de que um processo de pesquisa é uma experiência radicalmente empírica, contextual, localizada em espaço, tempo e ambientação, na qual todos os envolvidos, humanos, não-humanos e mais-que-humanos, põem-se a relacionar em condições absolutamente peculiares. No interior e no decorrer dessas relações, os procedimentos emergem, fruto da natureza mesma daquilo que acontece ${ }^{1}$.

Dito isso, espero que esteja suficientemente explícito porquê este texto, mesmo sendo um texto acadêmico, talvez não se pareça com um.

\footnotetext{
${ }^{1}$ Contudo, é preciso ter em mente que a pesuqisa pós-qualitativa não pretende negar as metodologias, métodos e técnicas pré-existentes, mas tão somente apresenta-se diferente deles (ST. PIERRE, 2017).
} 


\section{Pesquisa, docência, criação, urgências, tática}

Uma das formas assumidas pela pesquisa pós-qualitativa foi chamada de pesquisa-criação (research creation). Essa nomenclatura foi proposta por um grupo de pesquisadores canadenses, quando confrontados com a necessidade prática de informar aos órgãos financiadores de pesquisa de seu país o que era aquilo que faziam - práticas de arte, orientadas por uma ética da relação, em contextos universitários (MANNING, 2016). A partir dessa referência, forjei a noção de pesquisadocência-criação (NARDIM, 2017), buscando nomear aquilo que eu, assim como muitos colegas artistas que pesquisam educação em contextos universitários, geralmente (mas não necessariamente) vinculados aos desafios apresentados pela formação de professores, fazemos.

Assim como esse grupo, que precisou assumir uma forma fixa para a denominação de práticas cuja natureza é eminentemente fluida e imanente, eu, enquanto pesquisadora-docentecriadora, vivo a constante tensão entre, de um lado, o projeto ético-político de invenção de mundos que a experiência-em-arte pode possibilitar - especialmente quando depostos os limites que impõe entendê-la como forma-função (e linguagem) e, de outro, a urgência de desenhar, informar e disseminar, aos estudantes com quem compartilho aulas, práticas cujo caráter tático possa favorecer a manutenção mesma de sua vida. Do mesmo modo, me encontro frente ao desafio permanente de atestar à instituição de ensino em que trabalho, aos seus gestores e aqueles que a eles gerem, que nossos fazeres dialogam minimamente com as necessidades que querem fazer que sejam as nossas. Nós, hoje, sabemos o que gestores educacionais solicitam, já que os documentos e os rastros não cessam de dizê-lo: querem documentos, e rastros. Produção de evidências, de estatísticas. Provas permanentes de "pra quê serve" a arte em contextos educativos. Respostas para os frequentes "o que o artista quis dizer com isso?" de pais, de superiores ou deles mesmos. Concomitantemente, podemos também saber o que nos solicita a arte, e a aula entendida como um traço de pesquisa-docência-criação, pesquisa e docência e criação e pesquisa e docência... E o que ela nos pede não é o mesmo que os gestores nos solicitam. Como, portanto, administrar as forças desses dois âmbitos de nossa constituição - universidade e arte - com harmonia, de modo justo, e buscando perpetuar a duração dessa relação (o emprego desta professora, o futuro emprego do estudante) pelo maior tempo possível, com a maior qualidade possível? Como não ceder aos apelos da lógica neoliberal que progressivamente se apodera de nossos sistemas de educação, sem 
colocar-nos, contudo, fora dele, desviando de um confronto criativo ao encontro de um confronto potencialmente destrutivo - o desemprego, a vulnerabilidade social, quiçá o ostracismo?

A questão me emerge nesses termos pois, ao mesmo tempo em que o referencial teórico(prático) que aqui me inspira me oportuniza vislumbrar a potência de uma aula que possa ser experimentada como movimento de fazer-pensar - e não como forma fixa, o que, em minha compreensão, a afastaria da possibilidade da estesia - a consciência da situação socioeconômica dos estudantes, aliada àquela da precarização do fazer-pensar formação docente em nosso país, muitas vezes me reconduziu do investimento na intensidade da experiência da aula à facilitação ou mesmo transmissão de linguagens e códigos operacionais, à título de tática de sobrevivência para futuros professores. Isto é: muitas vezes deixei de praticar aquilo que compreendo como desejável para inventar o que ainda não existe, buscando apagar o incêndio da minha própria urgência de oferecer uma ou duas receitas que ancorassem o estudante no que é seguro, já existe, é aceito. Aí estão, portanto, dois campos de forças: um, ético-político, que me convoca: esse é o campo da aulacomo-arte-como-pesquisa. O outro, aquele que podemos chamar de "vida prática", em que residem a urgência da solução e a ansiedade, campo que se aproxima do primeiro e se intersecciona com ele lá, dentro da universidade, no plano de curso e na sala de aula. Esse é o campo do trabalho, do salário, do prestar contas, do medo do desemprego, da necessidade de manter-se em sala de aula. Já muito me soou inescapável. Enfim: para determinadas condições de vida ele pode até não se apresentar tão impositivo - dado que há pessoas que enfrentariam bastante bem o fato de não estarem empregadas em universidades ou, até mesmo, têm condições de lidar bem com o fato de não estarem sequer empregadas. Mas deixar de considerar esse campo, em meu entendimento, provoca uma série de implicações cuja assunção não me parece ética: em especial, a de não estar ativa e afetivamente junto daquelas e daqueles para os quais o exercício das potências de uma prática artística urge, por serem eles permanentes alvos dos ataques dos saqueadores neoliberalescos de vida - alunas e alunos.

A vivência dessa tensão - a tentativa de reequilíbrio permanente por sobre uma linha longa e muito elástica - muitas vezes esbarra na dificuldade de encontrar parceiros e parceiras para o necessário diálogo. É recorrente encontrar pesquisadores-docentes-criadores que tendem a conversar, em geral, de duas maneiras: ou negando veementemente a possibilidade de que uma coisa possa dialogar com a outra - isto é, reiterando a norma, que informa que ou você está de um 
lado da teoria, de um lado do pensamento, ou de outro; ou - segunda alternativa de minha generalização - assumindo que estou confusa, que não tenho clareza sobre as diferentes abordagens teóricas que busco friccionar, que preciso estudar mais e que sua influência (bemintencionada) poderá me bem-orientar rumo à abordagem que eles mesmos praticam. Ou, ainda: me cooptar.

De minha parte, ainda que tenha dado muita atenção a esses valorosos colaboradores e às suas contribuições, jamais estive tão certa de que preciso seguir tentando. Insistência, me parece, é a ação fundamental da pesquisa-docência-criação. Não se trata de desconsiderar a tradição intelectual de nosso campo, assim como também não se trata de respeitá-la a qualquer custo. Contudo, como sabemos, o mais respeitoso pupilo tende a ser aquele que, guiado pela mistura das orientações de seu tutor à sua intuição genuína, deságua em alguma espécie de subversão daquilo que the fora ensinado. Deixar de tentar e tentar investigar precisamente aquilo que a vivência me requisita seria uma impostura - isso, sim, seria um desrespeito.

Os demais pesquisadores-docentes-criadores (sim, numerosos), eu chamo de parças (NARDIM, 2017). Parceiros de um crime de vida. Armas multicoloridas.

É possível que eu esteja errada, e é possível que apenas não tenha visto respostas que já se vão apresentando. É possível que você mesma ou mesmo, que agora esteja lendo, leia aqui apenas ingenuidade, o texto como um espelho de uma sua vida anterior. Contudo, eu escolho investir no risco, e compreendo essa atitude como uma manifestação de intenções de escape do centramento no humano, no facilmente ideológico, no formal; na razão e no próprio centramento. Uma manifestação da pesquisa-docência-criação em si mesma, insistência na fuga de territorializações e enquadramentos no que tange aos campos moventes de pesquisar, ensinar e criar.

E, por falar em parças: Springgay e Rottas (2014) argumentam que, quando a arte é compreendida pela perspectiva da teoria produzida por esses parças com quem dialogamos - o que coincide com compreendê-la como um evento afetivo -, é impossível reduzi-la ao estritamente racionalizável, à interpretação e à dualidade forma-função. Torna-se, ainda segundo a autora, "uma força de relações que faz, do aprender, sensível e inarticulável - um excesso de linguagem" (SPRINGGAY; ROTTAS, 2014, p. 5).

Pesquisar-ensinar-criar é produzir excesso de linguagem, extravasar os limites (ainda que eventualmente maleáveis) do que já é dizível, do que já sabemos como, já sabemos quê, já sabemos. 
Quando produzindo artisticamente, na vivência de um processo de criação, tomamos o excesso que produzimos em nossos próprios campos subjetivos e o plasmamos em algo: a obra, o trabalho, esse excesso (ROLNIK, 2001). Criamos sobra para testemunhar e dar conta de nossa insuficiência, ineficiência, ineficácia. Não há momento de suficiência nas trocas com essa falta, com as matérias, com os contextos. Quando transladamos essa experiência para a sala de aula, introduzse a problemática dos corpos escolares todos, ou do próprio "escolar".

Quando infiltrada na universidade, o que poderá o corpo desta aula-arte perante a pulsão de estancá-la? À frente de gestores, de métricas (ainda não tão vigorosas para o campo do ensino das artes em nosso contexto), de urgências, qual ineficácia é possível dizer, a fim de sustentar a relação - as condições de existência da própria aula - pelo maior tempo possível, com a maior qualidade e consistência possível?

\section{A aula de arte como arte?}

A partir de minhas experiências enquanto participante de aulas de teatro, ao longo de 24 anos - contados desde a primeira aula de que participei, na escola, como atividade extracurricular e no contraturno, em 1996, aos 12 anos, ministrada pelo professor Anderson-Andy, que tinha DRT(!) -, uma aula de teatro tende a reunir diversas características que podem nos dar a vivê-la como uma aula-arte, ou um evento-arte. Certo está, porém, que não basta tratar-se de uma aula de uma linguagem artística para que esse caráter esteja garantido. Assim como não basta ser lúdico para que haja estesia. Certamente, os leitores e as leitores lembram-se de aulas de algumas das linguagens artísticas com as quais foi impossível conectar-se afetivamente, pelas quais passaram sem que nada, além de conteúdo (pintar assim ou assado), lhes tivesse passado. Assim, a reflexão acerca da viabilidade de uma aula-arte pode parecer muito mais pertinente às práticas de ensinoaprendizagem de conteúdos não-artísticos, do que àquelas dos conteúdos artísticos (estou me referindo a "conteúdos" por pensá-las aqui a partir da perspectiva convencional dominante). Aulasarte de conteúdos que-não-arte certamente farão a diferença em seu contexto. Mas... Visualize: quão terrível será a existência de uma aula-de-arte que não é uma aula-arte? Muito terrível. Precisamos evitá-la.

Em diversas ocasiões, tive a oportunidade de experimentar, em meu corpo, essa sensação. Tendo em vista as limitações da linguagem verbal para expressar essa experiência - e, em especial 
aquelas da linguagem escrita de caráter mais-ou-menos acadêmico - peço licença aos leitores e às leitoras para narrar uma dessas ocasiões.

Eu cursasva o doutorado, e participava de uma disciplina de práticas teatrais. Treinamento de atores. A disciplina fora ofertada concentrada, em duas semanas, nos períodos da manhã e da tarde, salvos os domingos. A professora, atriz muito experiente embora ainda jovem, exercia sobre mim uma espécie de fascínio. Não era um fascínio prévio, embora eu de fato admirasse o trabalho que a vira realizar em diversas peças. Era um encantamento físico, energético, presente, ativo, que acontecia para além e para quém do que se passava na sala, acima e abaixo das palavras que ela dizia, com e sem os exercícios que ela propunha. Assim como algumas vezes vejo um homem que não têm traços de beleza padrão, mas digo que ele é bonito, assumindo logo depois da constatação de sua ausência de beleza padrão por alguma amiga ou amigo, que ele é de fato charmoso, eu via charme ali, o que pode ser correspondente numa aula de teatro ao "charme" do homem hipotético. Era aquilo que não sei dizer, mas me atravessava e me presentificava ali, produzindo desejo de estar e produzindo "estando", produzindo senso de pertencimento, produzindo alegria sem provocar risadas, abrindo fendas no meu modo-de-ser tipicamente racional, lógico e arredio.

Então, não era o que ela dizia ou fazia, e de fato ela não produzia intencionalmente "charme", mas era como ela conduzia e organizava, como ela dançava com dito, o feito, nós, a sala, o tempo, o espaço. Rasgando a sala por entre exercícios, modulando a voz e a expressão, absolutamente una com o uno que todos nos fazíamos. Não era preciso uma história, uma narrativa, uma personagem para dar liga - não havia nada disso naqueles exercícios amparados em corpos e construções físicas. Dava-se passagem ao além-da-linguagem. Não repousava nas matérias, interpretadas como aquilo que costumam ser - tecido, bola, arco - mas eu não poderia negar que era absolutamente matérico. Eu era tomada por.

Em dado momento, já no final da tarde, muito calor, corpos suados exaustos de muitas horas de trabalhos corporais mas ainda correndo e pulando, encarnados de formas não-cotidianas. Com orientações gestuais da professora, que conosco fluía, organizamo-nos em duas fileiras, uma de cada lado da sala. Sem palavras, nossos corpos emanavam um pulso que, como uma agulha confusa, nos perfurava e atava com fino fio invisível, fazendo-nos vibrar-junto. Alguns gestos da professora pedem que atravessemos a sala, em duplas, um de cada fileira, com os corpos deformados que então 
praticávamos - doloridos corpos, suor, cansaço, o ar já faltando, mas eu estava muito ali. E foi então que, iniciando a travessia da sala, estabeleci contato visual com minha companheira de travessia, nos soube vinculadas, caminhei em sua direção e.

O insight aconteceu.

Estávamos sintonizados - corpos, coisas, tempos, espaços, palavras, vapores, luzes, a textura das paredes e o brilho do vidro da janela. Interconectados des-hierarquicamente.

Fui tomada por um misto de prazer corporal e intelectual, uma sensação de integração absoluta com o todo e, assim que desacelerei para então parar em meu novo lugar, já do outro lado da sala, sem poder mais sustentar o movimento e por isso me desvinculando do ritmo da sala, minha razão apresentou-se e cravou: estou vivendo uma obra de arte.

Uma parcela considerável da condição de arte da aula está não no conteúdo que aborda, mas na didática e na performance docente, e como esses elementos compõem-com e com-taminam o todo. Didática e performance, no caso, estão entendidas de maneira expandida, ou funcionando como palavras-chamariz para, mais uma vez, nos aproximarmos de coisas que não são exatamente o que esses termos representam no senso comum. Springgay e Zaliska (2016), falando sobre como o corpo teórico-prático com o qual dialogamos entende a produção de conhecimento, apresentam uma construção que também diz daquilo que acontece na aula de teatro que queremos aqui pensar, a aula-de-teatro-como-arte: nós nos debruçamos especialmente sobre o quê compõe-com no processo de produção da aula, e não exclusivamente no quem. As identidades, aqui, não importam. Não nos importam as representações. O que acontece, está antes e depois disso. Na matéria.

A materialidade rítmica da aula-de-teatro-como-arte, contudo, não é indício de que ela se esgota em si. Pelo contrário, ela é campo que expande possibilidades de produção de conhecimento - conhecimento encarnado, corporificado, sensível, vivenciado e a vivificar no além-sala.

\section{Como, enfim, produzir uma aliança tática da aula-de-teatro-como-arte com minha urgência?}

Por inúmeras vezes, ao longo de dez anos de trabalho no curso de Licenciatura em Teatro, testemunhei relatos de profissionais egressos do curso que, ao se depararem com a sala de aula, viam frustradas as suas expectativas de serem professores com características que eles chamam de diferentes; frustradas suas expectativas de produzir uma aula diferente, de mandarem às favas os 
planejamentos, as regras ou a necessidade de que o teatro atenda a determinados requisitos institucionais. Frustradas suas expectativas de que o teatro na escola não tenha uma função, não esteja a serviço de alguma ideia exterior à sala de aula ou de alguma outra disciplina escolar. O que eles vêem, em sua prática, é a necessidade de planejar, de prestar contas antes e depois, de justificar e de argumentar. Isso, pelo que pude vir ouvindo por esses tempos, nubla seu desejo e reverbera, na sala de aula, como impeditivo de um investimento criativo da vitalidade docente na criação.

Esses profissionais, quando estudantes, foram alunos de docentes que, de uma forma ou de outra, Ihes facultaram cultivar esse modo de pensar. Recentemente, em um encontro de docentes, um colega afirmava que "o teatro não serve para nada" - afirmação comum quando do contexto de debate sobre finalidades das artes. Poucos dias depois, uma colega comenta que avaliara diversos planos de cursos produzidos por estudantes de nosso curso e que eles demonstravam não saber como ou porquê planejar objetivos de ensino ou de aprendizagem, assim como pareciam não saber organizar uma sequência didática. Quando confrontados, respondiam a ela dizendo que isso não teria importância, já que os jogos de uma aula de teatro "não devem servir para nada". Respeito muito meus colegas que escolhem informar essa natureza de pensamento aos estudantes. Estou certa de que seu modo de pensar é legítimo e foi construído ao longo de uma longa trajetória de dedicação e pesquisa. Contudo, lançando mão de uma das mais valorosas oportunidades que a universidade nos oferece- - a de construir conhecimento por meio do debate, com respeito e sem pessoalização - é por discordar da propagação indiscriminada e descontextualizada desse discurso, especialmente por entre estudantes cuja sustentação financeira imediata depende da inserção em contextos de ensino formal, nos quais serão solicitados a atender à Base Nacional Comum Curricular, que passo a tratar da possibilidade de abordar taticamente uma aula-de-teatro-comoarte que, do alto de toda a sua disfuncionalidade (a disfuncionalidade que lhe atribuem os olhos dos sistemas produtivos), irá infiltrar-se, sorrateira, na escola - como água que corre pelo cano, sob a terra e, no roçar contínuo com matéria, produz a quase-invisível fresta pela qual passará a vazar continuamente, engendrando progressiva transformação, mas sem maior alarde. Até que os tijolos molhados da convencionalidade desfaçam-se sobre si mesmos.

Como você, pessoa leitora, pode ter já compreendido, eu jamais serei a pessoa a defender que aulas de teatro - e muito menos aquelas como-arte - devem ser projetadas para que produzam determinado efeito visível e funcional ao final da sessão - para que "sirvam" ou "funcionem", no 
entendimento opressor, produtivista, funcionalista dessas ações. Veja bem, pois eu não vim até agora falando de uma pesquisa que não tem método, uma arte que está além da linguagem, pessoas suadas sintonizadas com tecidos, coisas que vazam e extravasam...? Não, eu certamente não coaduno com essa perspectiva. Contudo, compreendo que tudo o que fazemos numa aula-deteatro-como-arte possui, necessariamente, uma infinidade de efeitos visíveis, para os quais precisamos tão somente atentar para então articular com nossa esperteza e promover, enfim, a continuidade da nossa relação com a escola, a sustentabilidade da nossa relação com a escola.

Por outro lado, também entendo que, em uma aula de teatro - e isso valerá tanto para aquela que como-arte para muitas das outras - professores têm expectativas com relação aos estudantes que não chegam a ser enunciadas, critérios avaliativos que não estão descritos em planos de curso, dos quais os estudantes podem não vir a ter consciência em nenhum momento, mas que acabam por refletir nas notas que são atribuídas ao final do curso. Algumas vezes, esses critérios invisíveis reúnem-se no plano de curso sob o rótulo "avaliação subjetiva" ou "avaliação docente". Foi por aí que eu comecei, quando tentei transferir para a vida prática as qualidades da minha aula-de-teatro-como-arte. Refletindo sobre a composição de um plano de curso para a disciplina Interpretação Teatral, perguntei-me: considerando que busco trabalhar no registro da aula-como-obra, que palavras posso utilizar para nos aproximar do sentido de movimentos, ações e atitudes que os estudantes estejam sendo instados a fazer, mas ainda não têm clareza disso?

Durante a realização de dois semestres dessa disciplina, durante o ano de 2018, investi na tentativa de criar condições-de-arte para as aulas, com ênfase no ritmo e na sintonização. Participei dessas aulas de modo bastante corporal, muitas vezes realizando as atividades propostas junto dos estudantes. Ao fim de cada uma das aulas, ainda na sala mas já sozinha, realizava sprints de escrita automática, com cinco minutos de duração marcados no relógio, com despertador, durante os quais eu deveria escrever sem recorrer a excessiva racionalização, sem tentar teorizar, sem parar de escrever ou retirar a caneta do papel e mantendo a ambiência da aula em foco. Foram, ao total, 28 escritas 13 da primeira oferta, 15 da segunda. Abaixo, transcrevo a escrita referente à aula 08 da primeira oferta:

Entregar o corpo ao chão, entrego também o meu dia, minha carne toda, carne de cotidiano. Daí dá pra sair leve e elevar-se até o lugar que eu preciso. A aula é subir acima do que antes, mesmo, 
é flutuar com o pé um pouquinho fora do chão. Mas flutuar denso, flutuar inteiro. Sinto como se eu estivesse dentro, mas não eles. Estamos separados, e só em pequenos momento parece que alguma coisa outra acontece. O cansaço, como sempre, o relaxamento, o relaxamento traz uma outra atenção, não é relaxar de já saber fazer, mas é relaxar de não querer acertar. Não querer acertar é um caminho, é a deambulância, deambulância na interpretação teatral não combina, não sei. Dá espaço para ser o outro junto.

$E$, aqui, a escrita referente à aula 11 da segunda oferta:

$*$

Não é só aprender a entrar em trabalho, mas aprender a entrar, aprender a trabalhar sem trabalho. Daí pode vir o aprender a porosidade, aprender a deixar-se atravessar, aprender o com, o estar-junto. Aprender a dançar sem dança. Como é que vibra sem vibrar? Eu sempre falo de aprender a entrar em trabalho, isso tem atenção, isso tem uma expiração funda e centrada. É um ritmo, mas não é subjetivo, não é eu te amo, afetinho, suas ideias, fofura, é abaixo disso, é frequencial. Difícil deslocar disso para as imagens, para personagens, mas ainda é possível, porque é o que acontece. Como fica essa transição? Como opera? É de uma coisa para a outra, contamina?

De posse desses escritos, bem como da experiência encarnada das tentativas de aulas-deteatro-como-arte, e com o objetivo de operar a manobra tática, passei a compor objetivos de aprendizagem para que constassem nos planos de curso subsequentes, assim como seus respectivos critérios de avaliação. Tais objetivos e critérios seriam avaliados progressivamente, e a eles seria atribuída uma nota referente à "percepção docente", que corresponderia a 50\% da nota final da disciplina.

Sendo os verbos as palavras tradicionalmente utilizadas na composição de objetivos de aprendizagem - dado que pretendem expressar aquilo que o estudante estará apto a realizar após ter participado do processo com êxito (e agora todas as palavras parecem inadequadas para retratar um processo de ensino-aprendizagem em teatro), debrucei-me especialmente à investigação de quais verbos melhor expressariam as habilidades afetivas que eu teria a expectativa de auxiliar o estudante a desenvolver - ou encontrar, ou ser-encontrado-por.

Segue o resultado - sempre parcial, sempre provisório: 


\section{OBJETIVOS DE APRENDIZAGEM}

No decorrer da unidade, espera-se que o(a) estudante faça-se apto (a):

- Deambular por entre movimentos, estados e forças, notando a eventual necessidade de assumir um em específico;

- Permitir-se ser atravessado(a) e afetado(a) pelas forças que a aula lança e circula.

- Sintonizar com os elementos da aula, mantendo, contudo, o discernimento das diferenças circundantes;

- Vibrar-com o coletivo.

(...)

\section{CRITÉRIOS DE AVALIAÇÃO}

Item 1: Percepção docente

A professora manterá, no decorrer de sua participação nas aulas, estado de atenção flutuante, a partir da qual poderá observar se os estudantes demonstram estado de atenção próprio à deambulação e manifestações corporais que induzam à interpretação de sintonização, vibraçãocom e atravessamento. Convém observar que a professora, como participante integral da realização, poderá aferir o exercício dessas qualidades e estados por meio de canais que, no momento presente, não sabe descrever.

Essa redação está sendo implantada pela primeira vez no semestre que, enquanto escrevo, está interrompido por uma crise sanitária mundial, decorrente da pandemia de COVID-19. Na primeira leitura do plano de curso - leitura que costumo realizar, integralmente, no primeiro dia de aulas, buscando rever coletivamente as propostas e estabelecer os pactos pedagógicos próprios daquele coletivo -, observei, nas expressões dos estudantes, três diferentes grupos: aqueles que pareciam não entender absolutamente nada do que estava acontecendo; aqueles que também não entendiam, e estavam desesperados; e, por fim, aqueles que aparentemente não levaram minha proposta nem um pouco a sério.

Na tentativa de explicitar aos estudantes as minhas intenções, compreendi algo que ainda não estava evidente: conectar-se com tais objetivos, ainda que de modo muito rudimentar e certamente 
muito distinto daquele que a proposição objetiva alcançar, impõe estabelecer uma relação com a palavra em seu estado de poesia. Ainda que se tratem de objetivos, de um documento, de uma fórmula tradicional e pela qual já passamos muitas vezes, será preciso que olhemos para aqueles verbos como vibráteis eles mesmos. A ideia de iniciar a relação com a aula de Interpretação Teatral pela palavra, e por uma palavra poética, me interessa. Sem, contudo, perder a noção de que se trata de um investimento tático em consolidar uma outra cultura institucional.

Uma experiência mais afinada com essa ideia, porém, ainda está por vir. 0 experimento paralisou-se, como nós nos recolhemos às nossas casas. Para não deixá-la repousar mais do que o necessário é que publico este primeiro texto. Agora, meus objetivos de continuidade para esse trabalho passam pelo seu auxílio, pessoa leitora. A intenção é continuar a desenvolver uma taxonomia para a aula-de-teatro-como-arte, popularizá-la e, hackeando o sistema universitário em que estamos inseridos, consolidá-la como fato "científico", disseminando-a entre espaços de conhecimento educacionais. Este texto é uma primeira tentativa nesse sentido. A partir de agora, conto com sua colaboração para continuarmos a estabelecer a aliança tática entre a aula-como-arte e as urgências institucionais de professoras e professores de teatro inseridos em nossas instituições de ensino.

\section{Referências}

MANNING, Erin. Ten propositions for research creation. COLIN, Noyale; SACHSENMAIER, Stefanie. Colaboration in performance practice: premisses, workings and failures. Londres: Palgrave Macmillan, 2016.

NARDIM, Thaise Luciane. Práticas de aprendizagem em arte da performance: pesquisa-docênciacriação por uma intensionalidade inominável. 2017. 1 recurso online (275 p.). Tese (doutorado) Universidade Estadual de Campinas, Instituto de Artes, Campinas, SP. Disponível em: <http://www.repositorio.unicamp.br/handle/REPOSIP/331242>. Acesso em: 10 maio 2020.

ROLNIK, Suely, "El arte cura?". Cuadernos Portátiles. Barcelona: Museu d'Art Contemporani de Barcelona (MACBA), 2001.

SPRINGGAY, Stephanie; ROTAS, Nikki. How do you make a classroom operate like a work of art? Deleuzeguattarian methodologies of research-creation. International Journal of Qualitative Studies in Education. Indiana/IN: 28(5): 1-21. Dez 2014. 
SPRINGGAY, Stephanie; ZALIWSKA, Zofia. Learning to be affected: Matters of pedagogy in the artists' soup kitchen, Educational Philosophy and Theory, 2016. DOI: https://doi.org/10.1080/00131857.2016.1216385 .

ST. PIERRE, Elizabet Adams. Writing post qualitative inquiry. Qualitative Inquiry, v. 24, p. 603-608, Out 2017. DOI: https://doi.org/10.1177/1077800417734567.

Artigo submetido em 10/04/2020, e aceito em 24/12/2020. 